\title{
Interactions in Composite Film Formation of Mefp-1/graphene on Carbon Steel
}

\author{
Jie Cheng ${ }^{1,2, *} \mathbb{0}$, Nanxuan Mei ${ }^{2,3}$, Sulin Chen ${ }^{4}$, Pengpeng Bai ${ }^{5}$, Bin Shen ${ }^{4}$, Jinshan Pan ${ }^{2}$ and Fan Zhang ${ }^{2,6}$ \\ 1 School of Mechanical Electronic \& Information Engineering, China University of Mining and \\ Technology-Beijing, Beijing 100083, China \\ 2 Division of Surface and Corrosion Science, Department of Chemistry, School of Engineering Sciences in Chemistry, \\ Biotechnology and Health, KTH Royal Institute of Technology, SE-10044 Stockholm, Sweden; \\ meinanxuanzz@163.com (N.M.); jinshanp@kth.se (J.P.); fz75@sussex.ac.uk (F.Z.) \\ 3 China International Engineering Consulting Corporation, Beijing 100048, China \\ 4 School of Mechanical Engineering, Shanghai Jiao Tong University, Shanghai 200240, China; \\ chensulin@sjtu.edu.cn (S.C.); binshen@sjtu.edu.cn (B.S.) \\ 5 State Key Lab of Tribology, Tsinghua University, Beijing 100084, China; baipengpeng@mail.tsinghua.edu.cn \\ 6 Department of Engineering and Design, University of Sussex, Brighton BN19RH, UK \\ * Correspondence: jiecheng@cumtb.edu.cn
}

check for updates

Citation: Cheng, J.; Mei, N.; Chen, S.; Bai, P.; Shen, B.; Pan, J.; Zhang, F. Interactions in Composite Film Formation of Mefp-1/graphene on Carbon Steel. Coatings 2021, 11, 1161. https://doi.org/10.3390/ coatings11101161

Academic Editor: Kyong Yop Rhee

Received: 5 September 2021

Accepted: 23 September 2021

Published: 27 September 2021

Publisher's Note: MDPI stays neutral with regard to jurisdictional claims in published maps and institutional affiliations.

Copyright: (c) 2021 by the authors. Licensee MDPI, Basel, Switzerland. This article is an open access article distributed under the terms and conditions of the Creative Commons Attribution (CC BY) license (https:/ / creativecommons.org/licenses/by/ $4.0 /)$.

\begin{abstract}
Mefp-1 adhesive protein derived from marine blue mussels, together with the 2D material graphene, was used to build the green composite film with enhanced anti-corrosion property and mechanical strength. The corrosion inhibition of the composite film, formed by different methods, was evaluated by using electrochemical impedance spectroscopy. The non-degraded adhesion of the composite film to the carbon steel substrate was proved by nano-scratch tests. Infrared spectroscopy was utilized to investigate the film formation process and "three-body interactions" between Mefp-1, graphene and carbon steel surface. The results show that the Mefp-1 adsorbs on the carbon steel surface mainly through the covalent bond between catechols and Fe(III). Meanwhile, Mefp-1 can bond to non-adhesive graphene by forming hydrogen bonds and $\pi-\pi$ interaction non-covalent bonds, which facilitate the formation of a robust Mefp-1/graphene composite film on the carbon steel surface.
\end{abstract}

Keywords: graphene; Mefp-1; corrosion; adhesion; infrared spectroscopy

\section{Introduction}

Mussel adhesive proteins (MAPs) extracted from the feet of marine blue mussel have been successfully applied to form films on various surfaces [1]. Until now, at least six kinds of adhesive proteins have been identified from the mussels, which are denoted as Mefp-1 to Mefp-6 [2]. Among these, Mefp-1 is firstly purified from the blue mussel so that it is ready for large scale production. As such, Mefp-1 is more often used in research. The high adhesive strength, cross-linking and film forming properties of Mefp-1 are attributed to the high content (10 15 mol.\%) of peptidyl (3,4-di-hydroxypheny)-L-alanine (DOPA) in its molecular sequence [3]. DOPA in Mefp-1 could form covalent bonds, hydrogen bonds and coordinate covalent bond with surfaces and ions [1]. Researches have proven that the catechol functional groups in the primary structure of DOPA could form complexes with $\mathrm{Fe}^{3+}$, and the $\mathrm{Fe}^{3+} /$ DOPA complexes provide the reversible metal-mediated bridging of Mefp-1 films [4,5]. The oxidation of DOPA to dopaquinone enables the cross-linking of Mefp-1 [6]. All these properties of DOPA could enhance the compactness and adhesion to substrates during film formation of Mefp-1 on metal surfaces. Considering such properties, researchers further explored the corrosion resistance of $M e f p-1$ film on metal surfaces and proved that it exhibits considerable anti-corrosion properties. A thin pre-adsorbed Mefp-1 film on pure metals (Fe, $\mathrm{Mg}$ ) and alloys (carbon steel, stainless steel, magnesium alloy) could provide increased corrosion inhibition during extensive periods of exposure to corrosive solutions [7-11]. 
Since Mefp-1 is an environmentally-friendly and powerful building block for spontaneous deposition of composite thin films on bulk metals, where the deposited film could adapt for wide functional uses. In recent years, strategies have been proposed to build composite film using the Mefp- 1 and other micro/nano-additives to achieve multifunctional properties, in addition to better corrosion resistance. The composite films of sub-micron thickness, composed of Mefp- 1 and $\mathrm{CeO}_{2}$ nanoparticles, provide excellent corrosion protection for carbon steel. Moreover, the Mefp- $1 / \mathrm{CeO}_{2}$ film possesses a self-healing ability, which is attributed to the formation of DOPA- $\mathrm{Fe}^{3+}$ complexes [12,13]. Thin films that are "smart" and "multifunctional", apart from "green" and "effective", are continuously sought for various industrial applications. Recently, emerging technologies have been proposed to develop multifunctional coating using Mefp-inspired 2D material. Graphene is the most representative 2D material, which has shown excellent tribology properties as a solid lubricant additive $[14,15]$, but its durability is limited due to its weak adhesion to the substrate [16-18]. Considering the advantages of Mefp- 1 and graphene, a surface film combining both materials could potentially achieve both wear and corrosion resistance, and long service life due to good adhesion to substrate. Pioneering investigations explored the possibility of making composite film using Mefp-1 and graphene micro-sheet, and the formed composite film turned out to be corrosion- and wear-resistant on the carbon steel surface $[19,20]$. However, a deep understanding of the interaction between Mefp-1, graphene and carbon steel at the film/base interface needs to be explored, as it is crucial to our understanding of film formation and in further development of sustainable multifunctional surfaces.

In this study, two different film preparation methods were used to prepare the Mefp1 /graphene composite film on the carbon steel surface, and two main issues were investigated related to the Mefp-1/graphene composite film formation. The first issue is the mechanical degradation of the film, which was evaluated by the adhesion property of the film to the substrate using the nano-scratch test. The second issue is the "three-body interactions" between Mefp-1, graphene and carbon steel surface, which was investigated by using infrared reflection-adsorption spectroscopy (IRAS). The IRAS technique was the most commonly used to study the kinetics of reactions of proteins on surface $[5,21,22]$. Based on the results of the in-depth fundamental investigations, the film formation of the Mefp-1/graphene composite on the carbon steel surface was proposed.

\section{Experimental}

\subsection{Mefp-1/graphene Film Preparation}

The substrate used was cold rolled carbon steel (DC 01, 1.0330), provided by IVF, Stockholm, Sweden. The substrates were ground with abrasive paper successively to $1200 \#$. Mefp-1 (92 wt.\% in purity, Biopolymer Products AB, Göteborg, Sweden) was stored in $1 \mathrm{wt} . \%$ citric acid solution in the dark at $4{ }^{\circ} \mathrm{C}$. Graphene sheets, with 3-8 layers and ca. $1 \mu \mathrm{m}$ lateral size, were produced by ultrasonic stripping in Shanghai Jiaotong University, Shanghai, China.

Two methods were used for the preparation of Mefp-1/graphene composite film. The first is the immersion method. Amounts of of $0.1 \mathrm{mg} / \mathrm{mL}$ Mefp- 1 and $0.05 \mathrm{mg} / \mathrm{mL}$ graphene were dispersed in $1 \%$ citric acid solution, respectively. The $\mathrm{pH}$ value of the solution was adjusted to 6.34 using $\mathrm{NaOH}$, in order to improve the adsorption and film compactness of Mefp-1, compared with the previous investigation [20]. The carbon steel substrate was first immersed in Mefp-1 solution for $40 \mathrm{~min}$ and then in graphene solution for $20 \mathrm{~min}$. The procedure was repeated 4 times. This is the so-called alternative immersion method. The one-step immersion method was also tried for comparison. In the one-step immersion, the substrate was immersed in a mixed solution containing Mefp-1 and graphene for $60 \mathrm{~min}$.

The second is the electrophoresis method. The solution contained $1 \mathrm{mg} / \mathrm{mL} \mathrm{Mefp-1}$ and $0.5 \mathrm{mg} / \mathrm{mL}$ graphene. The electrophoresis voltage was $10 \mathrm{~V}$ and the electrophoresis duration was 5 min. 


\subsection{Corrosion Inhibition Measurement}

The corrosion inhibition of the Mefp-1/graphene composite film was evaluated using the electrochemical impedance spectrum (EIS, Gamry Instruments, Philadelphia, PA, USA). The EIS measurements were performed for the samples exposed to $0.1 \mathrm{M} \mathrm{NaCl}$ solution. The measurements were conducted on an electrochemical potentiostat (PGSTAT302N, Autolab, Landmark, Netherlands). The grounded carbon steel sample with no film acted as the control sample. The EIS measurements were conducted at the open-circuit potential for up to 9 days of exposure, with perturbation amplitude of $10 \mathrm{mV}$. The frequency range is from $10,000 \mathrm{~Hz}$ to $0.01 \mathrm{~Hz}$. The polarization resistance, as an evaluation of the corrosion resistance of the film, was determined after the measurement. The EIS spectra were fitted using the Nova1.10 software with a simplified equivalent circuit, each element of which has strong physical meaning.

\subsection{Mechanical Adhesion of the Film}

The nano-scratch technique measures the shear adhesion strength of coatings to substrate [23]. It is commonly applied to evaluate the durability of thin films under the application of several $\mathrm{mN}$ to $\mu \mathrm{N}$ scratch load. In this experiment, a nano-indenter (G200, Keysight technologie, New York, NY, USA) with lateral displacement resolution $0.01 \mathrm{~nm}$ and load resolution $50 \mathrm{nN}$ was used to conduct the nano-scratch tests. A ramping load was applied during the scratch and the maximum scratch load was $100 \mathrm{mN}$. The scratch length was $800 \mu \mathrm{m}$, and the scratch velocity was $30 \mu \mathrm{m} / \mathrm{s}$. The scratch depth was measured by the displacement into the surface and the topography of the scratch was observed using a surface profilometer (Talysurf PGI, Taylor Hobson, Leicester, UK).

\subsection{Adsorption and Interactions during Film Forming}

Infrared reflection-adsorption spectroscopy (IRAS) is based on the absorption of infrared light due to the excitation from the ground to a higher energy level. It can give information of molecular structure and functional groups. The adsorption of Mefp-1 on carbon steel, and the interactions between graphene and Mefp-1 were investigated using FTIR spectrometer (Tensor 37, Bruker, Billerica, MA, USA) equipped with an MCT (Mercury Cadmium Telluride) detector with a ZnSe. Spectra were based on 512 scans for both the samples and the background. A background spectrum on carbon steel with surface processed in $1 \mathrm{wt}$.\% citric acid was collected for all the measurements.

\section{Results and Discussion}

\subsection{The Effect of Film Preparation Methods on Corrosion Protection Performance}

The corrosion inhibition of the Mefp-1/graphene composite film has been evaluated by the EIS experiments. The electrochemical impedance spectra of the Mefp-1/graphene composite film formed with different preparation methods were obtained in $\mathrm{NaCl}$ solutions for up to 9 days of exposure. Figure 1a shows the Bode plots of the films prepared by alternative immersion and one-step immersion after 8 days' immersion in $\mathrm{NaCl}$ solution. The composite film on carbon steel behaves like one single layer, which could be fitted by the simplest equivalent circuit $R_{S}\left(R_{p} C P E\right)$, as shown in the Insert of Figure 1a [24]. $R_{S}$ is the resistance of the solution and $C P E$ is a constant phase element representing the non-ideal capacitance of the electrolyte/metal interface. $R_{p}$ is the polarization resistance, which indicates the corrosion resistance of the measured film. Therefore, a higher $R_{p}$ value means better corrosion inhibition property of the film. The $R_{p}$ values are summarized in Figure $1 \mathrm{~b}$. The $R_{p}$ of the film, prepared by the alternative immersion method, remained stable at around $1.9 \mathrm{k} \Omega \cdot \mathrm{cm}^{2}$ during the exposure, suggesting stable protection of the formed film against corrosion. In relation to the film prepared by the one-step immersion method, the $R_{p}$ of the composite film is slightly larger than the bare carbon steel at initial stage of exposure, but noticeably increases with the prolonged immersion time after 4 days, which peaks at ca. $2.8 \mathrm{k} \Omega \cdot \mathrm{cm}^{2}$ after 8 days' exposure. An increase in $R_{p}$ during exposure is due to the integration of the corrosion products into the film and the enhanced complexation 
between Mefp- 1 and iron ions, as the Fe ions and corrosion products take time to be released from the carbon steel surface $[5,25]$.

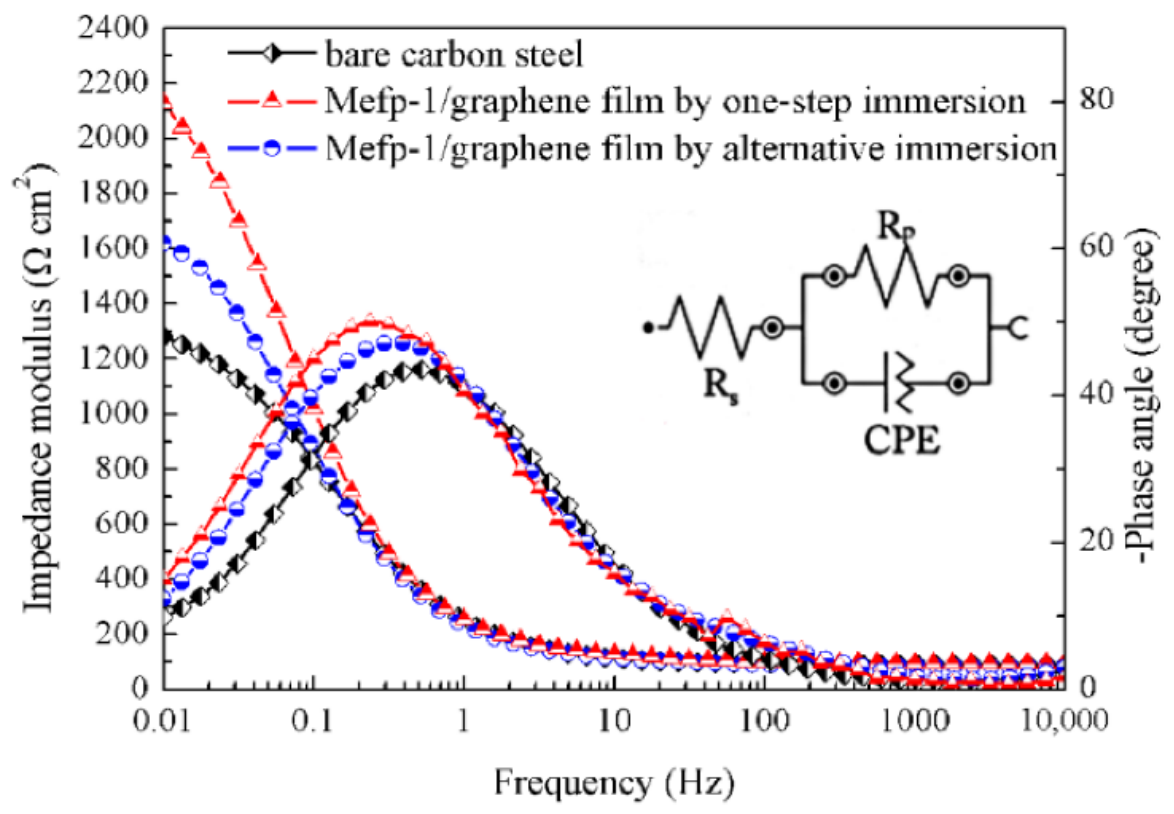

(a)

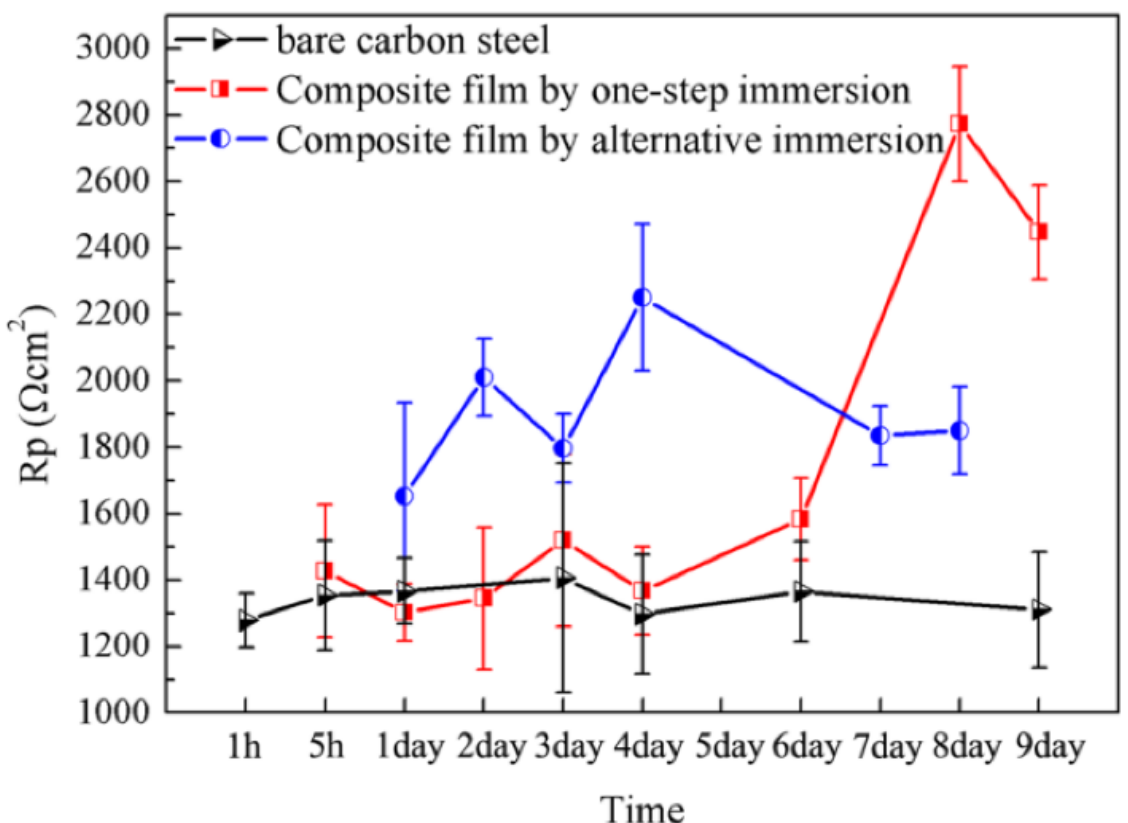

(b)

Figure 1. Electrochemical impedance spectrum (EIS) of the composite film on carbon steel prepared by immersion methods: (a) Bode plots after 8 days exposure; (b) changes of polarization resistance $(R p)$.

Similarly, Figure 2 shows the Bode plots and calculated $R_{p}$ value of the electrochemical impedance for the Mefp-1/graphene composite film prepared by the electrophoresis method. The results could be fitted using the same equivalent circuit $R_{S}\left(R_{p} C P E\right)$, where the film resistance dominates the impedance response. The $R_{p}$ of the composite film in 
Figure $2 \mathrm{c}$ shows a significant increase with prolonging of the exposure time. It increases rapidly during the first few days and stabilizes at high level of around $3.0 \mathrm{k} \Omega \cdot \mathrm{cm}^{2}$ after 3 days of exposure, which shows good corrosion inhibition effect on the carbon steel.
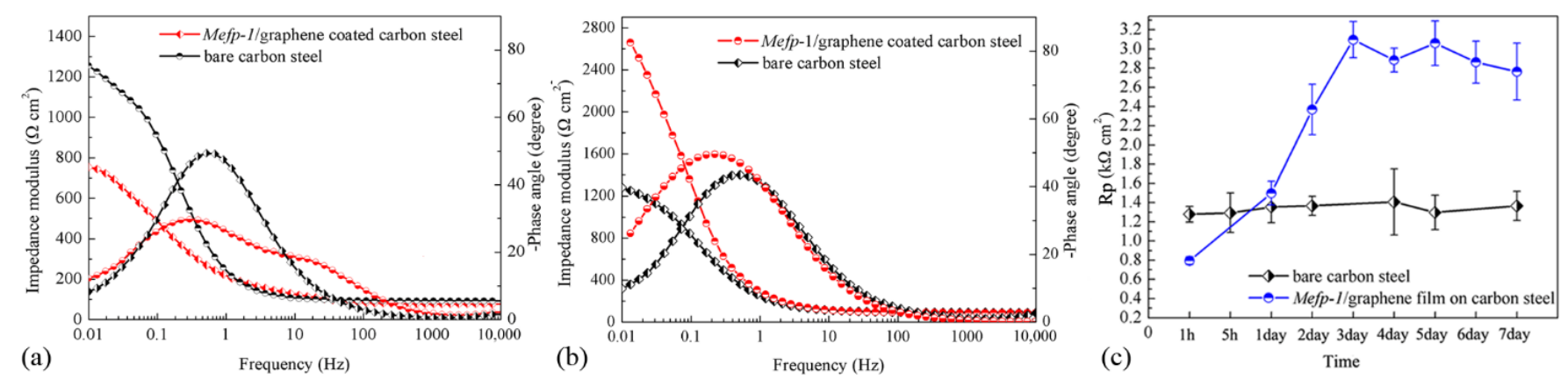

Figure 2. Electrochemical impedance spectrum (EIS) of the composite film on carbon steel prepared by electrophoresis method: (a) Bode plots after 1 day exposure; (b) bode plots after five day exposure; (c) changes of polarization resistance $(R p)$.

The EIS results indicate that film preparation methods can influence the corrosion inhibition effects of the formed composite films. Overall, the composite film prepared by the one-step immersion method and the electrophoresis method show the most improved anti-corrosion properties. However, these films are not suitable for short-time temporary applications.

\subsection{Interfacial Adhesion of the Composite Film}

The adhesion of pristine graphene onto carbon steel could not be directly measured because there is little chance that graphene could adhere to the substrate. As it is well-known that Mefp-1 has good affinity to all kinds of substrates, it is a good idea to compare the adhesion of Mefp-1/graphene film with Mefp-1 film using the nano-scratch tests. Figure 3 displays penetration depth obtained from the nano-scratch tests, performed on a Mefp1/graphene composite film (Figure 3a,c) and the Mefp-1 film (Figure 3b,d). The morphology of the scratch was observed by the light microscopy, which could help to detect the point of complete delamination. Figure 4 shows the coefficient of friction (COF) results of the two films. Overall, the COF and the penetration depth increase as the the applied normal force and the scratching length increase, and the COF of Mefp-1/graphene composite film is higher than that of Mefp-1 film, which might be attributed to the graphene flakes inside the film. The delamination point of the films could be determined based on the transition points on such curves [26]. It should be noted that both the Mefp-1 and Mefp-1/graphene films are soft thin films, the delamination of which is challenging due to the technical limitations. Combining the slope changes of the COF and penetration curves, as well as the optical observation of plastic deformation, the average critical loads of is determined at $15.4( \pm 2.1) \mathrm{mN}$ for Mefp-1/graphene film and $13.8( \pm 1.9) \mathrm{mN}$ for Mefp-1 film, indicating the initiation of edge cracking of the film [27]. There are no statistically significant differences in the critical loads among the two films. Since graphene alone could not adequately adhere to the substrate, a binder is often used to modify the surface of either graphene or the substrate surface before the film deposition $[18,28]$. The above results show that the Mefp-1/graphene composite film presents sufficient and non-degraded adhesion to the carbon steel compared with that of Mefp-1, which has been widely recognized as super bio-binder [29]. 


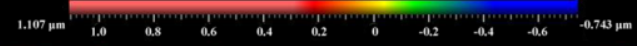

(a)

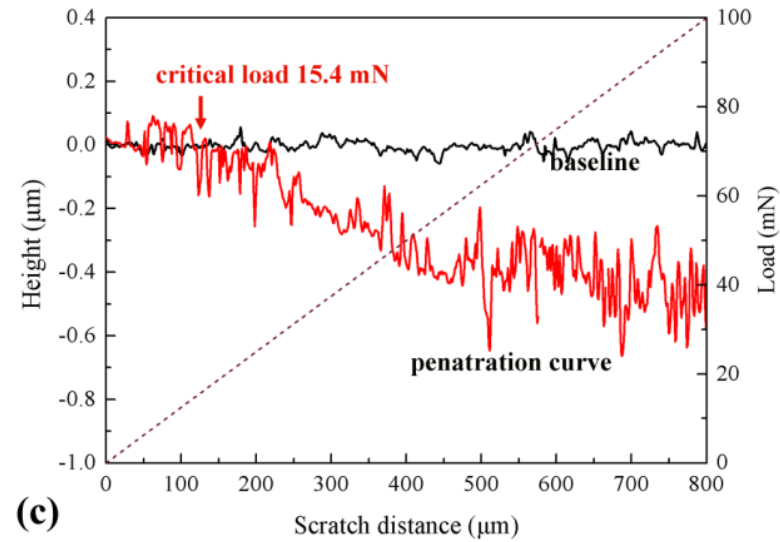

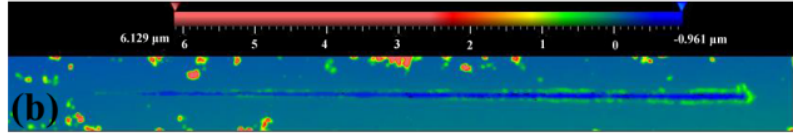

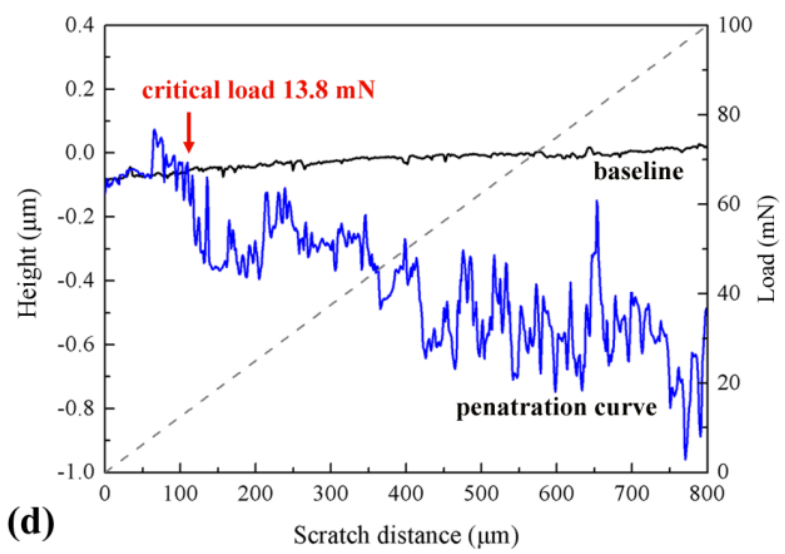

Figure 3. Results of the nano-scratch tests. Left: Results of Mefp-1 film on carbon steel. Right: Results of Mefp-1/graphene composite film on carbon steel. $(\mathbf{a}, \mathbf{b})$ Morphology of the scratch. $(\mathbf{c}, \mathbf{d})$ The penetration curves as a function of the scratch distance. The dashed line indicates the applied ramping load.

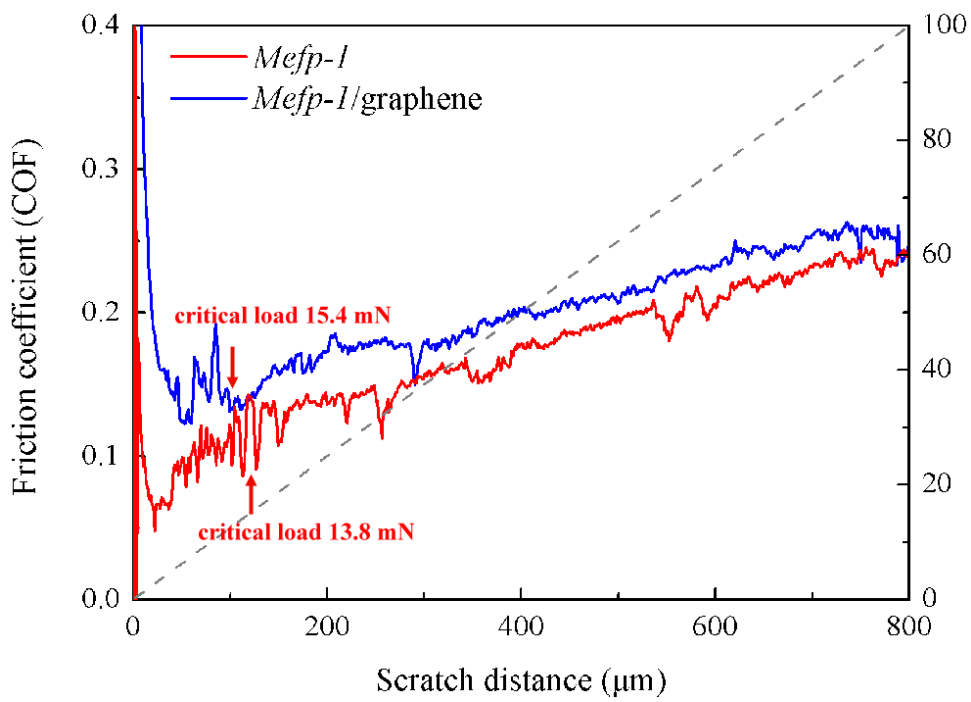

Figure 4. Coefficient of friction (COF) changes in the nano-scratch tests. The dashed line indicates the applied ramping load.

\subsection{Infrared Spectra of Mefp-1/graphene Composite Film}

The interactions between Mefp-1 and graphene could be observed from the infrared (IR) spectra. IR spectra results were collected at different time during film deposition, as shown in Figure 5. The red, green and gray areas represent the characteristic infrared peaks of amid I (1600-1700 $\left.\mathrm{cm}^{-1}\right)$, amid II (1500-1600 $\left.\mathrm{cm}^{-1}\right)$ and amid III $\left(1350-1450 \mathrm{~cm}^{-1}\right)$, which could be used to identify the protein [30]. The intensity of each characteristic band in Figure 5 grows with the prolonged deposition time, indicating the continuous of the adsorbed film. In Figure 5a, band (a) at $1657 \mathrm{~cm}^{-1}$ refers to $\mathrm{C}=\mathrm{O}$ stretch of the amide groups in the backbone, which is sensitive to hydrogen bond [31,32]. Band (b) at $1525 \mathrm{~cm}^{-1}$ is mainly associated with the N-H stretching in the backbone. Band (c) at $1480 \mathrm{~cm}^{-1}$ and Band (d) at $1423 \mathrm{~cm}^{-1}$ are related with the $\mathrm{C}-\mathrm{C}$ stretching of the aromatic ring of the DOPA side chain. Band (d) arises from a considerable fraction of catechols of the DOPA residues being complexed with $\mathrm{Fe}(\mathrm{III})$, but potentially from less symmetrical complexes [33,34], and thus Band (d) is a diagnostic signal of (DOPA) Fe(III) complex. Similarly, Band (e) at 
$1251 \mathrm{~cm}^{-1}$ represents the $\mathrm{C}-\mathrm{O}$ stretch of the hydroxyl groups in DOPA, the appearance of which indicates the symmetrical coordination of three catechols to Fe(III) [5]. In Figure 5b, the presence of graphene causes evident changes of the IR spectra compared with Mefp-1 alone. The characteristic bands (a-e) more or less shifts. The comparison of bands shift between Mefp-1 and Mefp-1/graphene film are listed in Table 1. Besides, bands at $962 \mathrm{~cm}^{-1}$ and $1784 \mathrm{~cm}^{-1}$ (only visible in Figure $5 \mathrm{~b}$ ) are associated with $\mathrm{C}=\mathrm{O}$ bending in $\mathrm{R}-\mathrm{COOH}$ and $\mathrm{C}=\mathrm{O}$ stretching in $\mathrm{R}-\mathrm{COOH}$, respectively. The $\mathrm{C}=\mathrm{O}$ bending might overlap with other $\mathrm{C}-\mathrm{H}$ out of plane bending [35]. They are less relevant to the work and will not be discussed below.
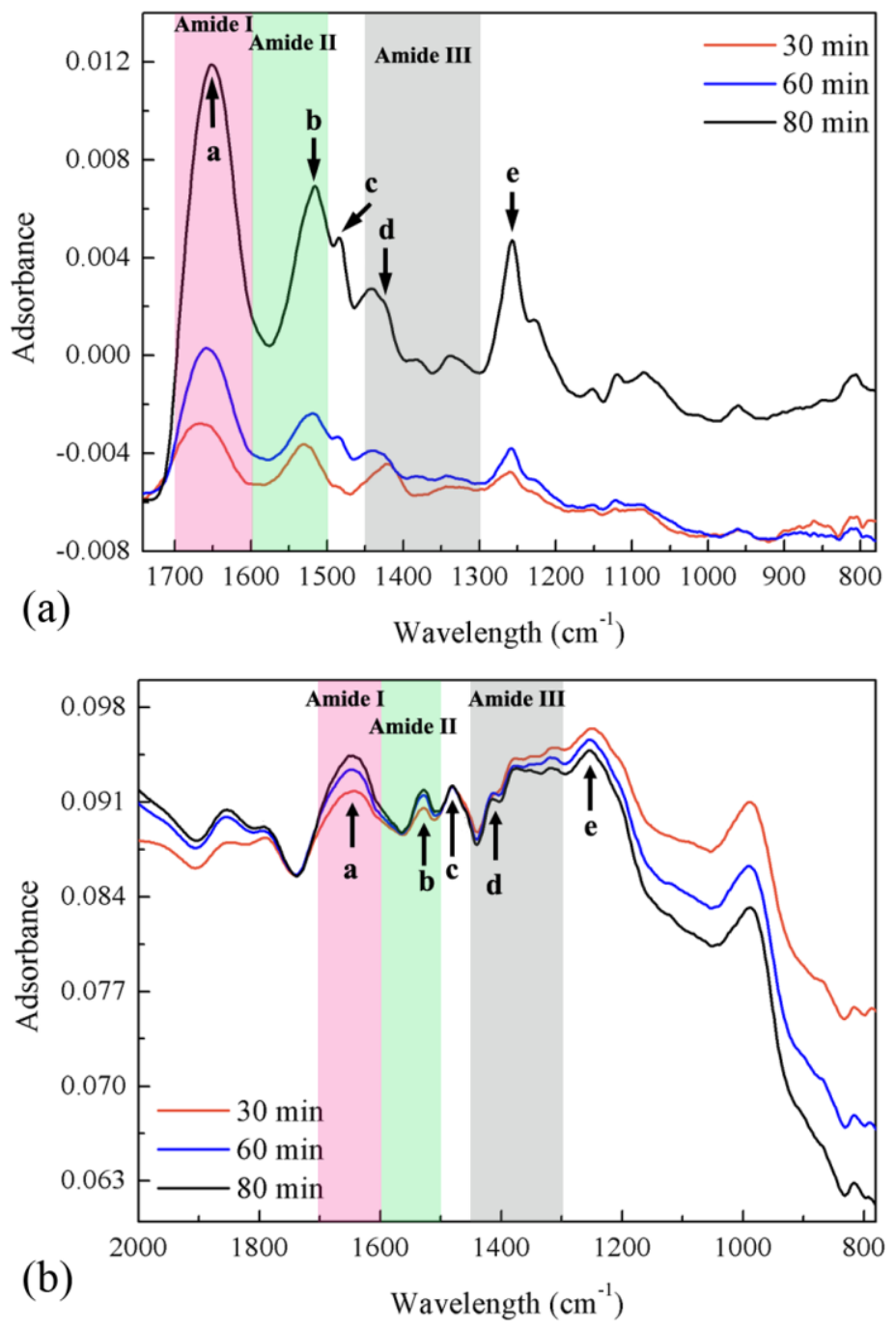

Figure 5. Infrared spectra of (a) Mefp-1 film and (b) Mefp-1/graphene film on carbon steel surface with different film growth time.

Table 1. Assignments of characteristic peaks in Figure 5.

\begin{tabular}{lcc}
\hline \multicolumn{1}{c}{ Assignment and Remarks } & Mefp-1 & Mefp -1/graphene \\
\hline a: mainly C=O stretch in Amide I & 1657 & 1644 \\
sensitive to hydrogen bond & 1525 & 1528 \\
b: mainly N-H bending in Amide II & 1484 & 1480 \\
c: C-C ring stretch in DOPA & 1423 & 1414 \\
d: C-C ring stretch in DOPA & 1258 & 1251 \\
diagnostic signal of tris (DOPA) Fe(III) complex & & \\
e: C-O stretch in DOPA & & \\
\hline
\end{tabular}


Figure $6 \mathrm{a}, \mathrm{b}$ shows the comparison of the IR spectra between Mefp-1 and Mefp-1/graphene composite film at $60 \mathrm{~min}$ film growth time. There are large differences in the band region between 1300-1450 $\mathrm{cm}^{-1}$ (C-N stretching, N-H bending) between Mefp-1/graphene and Mefp-1, because this region mainly consists of vibrations of amide III, which is sensitive to the secondary structure changes of proteins [36]. It is obvious that Bands (a), (c), (d) and (e) broaden and shift to lower wavenumber (Figure 6a). These bands are all associated with the vibrations of DOPA. Band (b) shows a negligible shift which is beyond the resolution of the apparatus $\left(4 \mathrm{~cm}^{-1}\right)$. The broadening and red shift of the characteristic bands after the integration of graphene in the film are most probably due to the hydrogen bonds forming between DOPA functional group in Mefp-1 and hydroxyl groups in graphene [37], which are organic residuals generated during material preparation (shown in Figure 6b). The hydrogen bonding could result in a tight molecular packing, which enhances the interaction between Mefp-1 and graphene [38]. It should also be noted that a peak around $1610 \mathrm{~cm}^{-1}$ was generated in the Mefp-1/graphene composite film, which contributes to the asymmetry of Band (a), as clearly shown in Figure 6a. The appearance of the peak was attributed to $\mathrm{C}=\mathrm{C}$ stretching of the catechol ring, and indicates better ordering of the catechol rings after the addition of graphene [39]. This observation could be explained by the enhanced $\pi-\pi$ stacking between the catechol rings of DOPA or between catechol rings in DOPA and hexatomic rings in graphene [19]. Such a $\pi-\pi$ interaction can be another type of weak non-covalent bond interaction in this system [40].
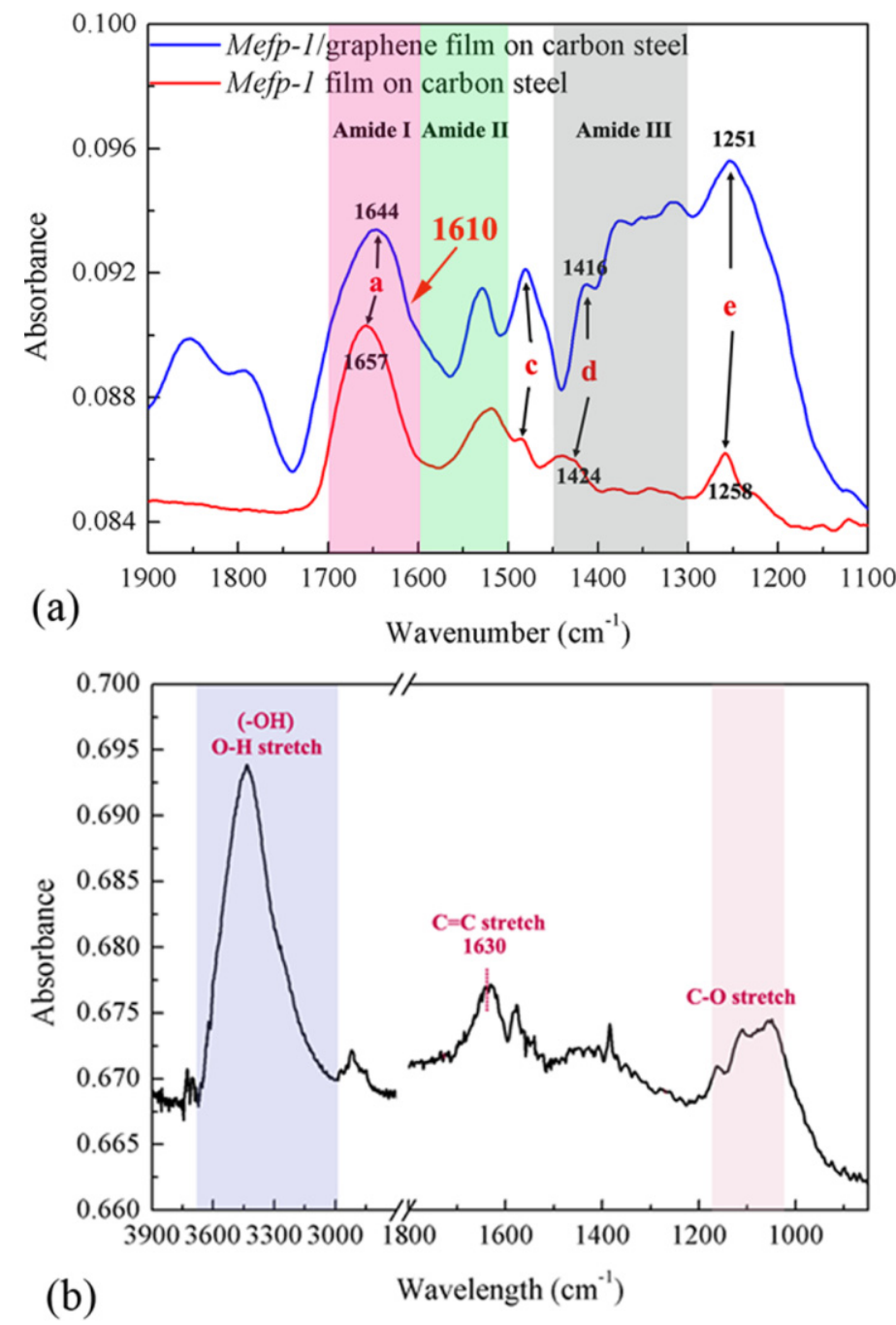

Figure 6. (a) Infrared spectra of Mefp-1 film and Mefp-1/graphene film grown on carbon steel surface for $60 \mathrm{~min}$; (b) infrared spectra of pure dry graphene. 
The schematic of the film formation of Mefp-1/graphene on carbon steel surface is illustrated in Figure 7. The adsorption of Mefp-1 on carbon steel surface is mainly through the covalent bond between catechols and Fe(III), forming (DOPA)Fe(III) complexes. Graphene alone could not adhere to the carbon steel substrate, but there formed noncovalent bonds between graphene and Mefp-1. One type is the hydrogen bonds between DOPA side chains and hydroxyl groups in graphene, and the other type is the $\pi-\pi$ interaction between graphene hexagonal ring and catechol rings in DOPA.

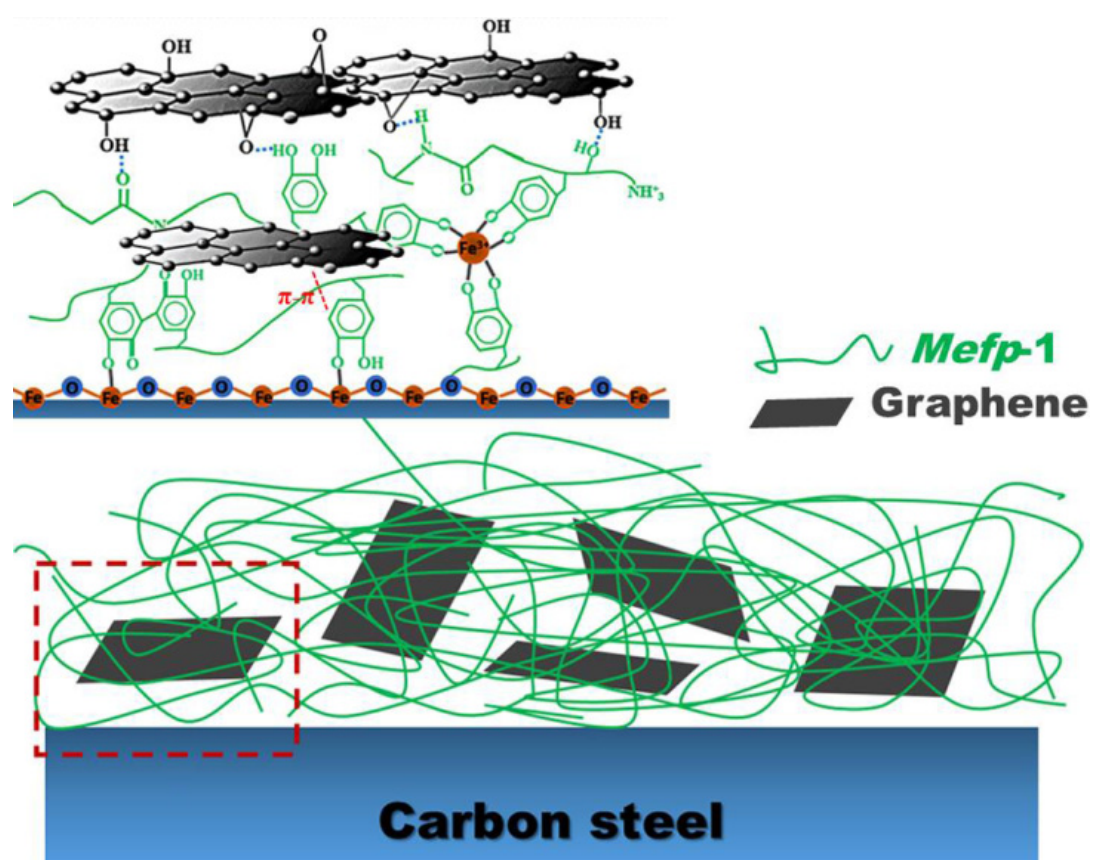

Figure 7. Schematic of the formation of Mefp-1/graphene composite film on carbon steel.

\section{Conclusions}

In this study, the Mefp-1/graphene composite films were prepared using both immersion method and electrophoresis method on the carbon steel surface. The mechanical adhesion and anti-corrosion properties of the film were explored. The film formation, especially the "three-body interactions" within the composite film was analyzed using Infrared reflection-adsorption spectroscopy (IRAS). The data set leads to the following conclusions:

(1) Electrochemical impedance spectroscopy (EIS) results demonstrate that film preparation method influences the corrosion inhibition property of the formed Mefp-1/graphene films on the carbon steel. The film prepared by the one-step immersion and the electrophoresis methods show the most improved anti-corrosion properties, which increase with prolonged immersion time in the corrosive solution, and are suitable for applications that require long-term corrosion protection. The film formed by the alternative immersion method is more suitable for short term applications.

(2) Nano-scratch test results prove that Mefp-1/graphene composites could provide sufficient and non-degraded adhesion to the carbon steel compared with that of Mefp-1.

(3) IRAS results show that the adsorption of Mefp-1 on carbon steel surface is mainly through the covalent bond between catechols and Fe(III); Hydrogen bonds and $\pi-\pi$ interaction non-covalent bonds could be formed between graphene and Mefp- 1 . These interactions contribute to the robust film formation process of Mefp-1/graphene on the carbon steel surface.

Future work will focus on the anti-bacterial properties of the Mefp-1/graphene composite film, in order to explore its potential use as a multi-functional coating on ocean ships. 
Author Contributions: J.C. conceived the original idea, carried out the nano-scratch experiments and drafted the manuscript. N.M. carried out the IR experiments and data analysis. S.C. and B.S. participated in the composite film preparation. P.B. participated in the design of the experiments and coordination. J.P. and F.Z. helped supervise the project and modified the manuscript. All authors have read and agreed to the published version of the manuscript.

Funding: The authors greatly acknowledge the financial support from the National Natural Science Foundation of China (No. 52075037, 51805292), and the Swedish Foundation for International Cooperation in Research and Higher Education (STINT project for Swedish-China collaboration, grant No. CH2017-7255).

Institutional Review Board Statement: Not applicable.

Informed Consent Statement: Not applicable.

Data Availability Statement: The data presented in this study are available in [Interactions in Composite Film Formation of Mefp-1/graphene on Carbon Steel].

Conflicts of Interest: The authors declare no conflict of interest.

\section{References}

1. Lee, H.; Dellatore, S.M.; Miller, W.M.; Messersmith, P.B. Mussel-Inspired Surface Chemistry for Multifunctional Coatings. Science 2007, 318, 426-430. [CrossRef]

2. Waite, J.H.; Qin, X. Polyphosphoprotein from the Adhesive Pads of Mytilus edulist. Biochemistry 2001, 40, 2887-2893. [CrossRef] [PubMed]

3. Zhang, F.; Xie, G.; Pan, J. Tunable Adsorption and Film Formation of Mussel Adhesive Protein by Potential Control. Langmuir 2017, 33, 8749-8756. [CrossRef] [PubMed]

4. Harrington, M.J.; Masic, A.; Holten-Andersen, N.; Waite, J.H.; Fratzl, P. Iron-Clad Fibers: A Metal-Based Biological Strategy for Hard Flexible Coatings. Science 2010, 328, 216-220. [CrossRef]

5. Zhang, F.; Sababi, M.; Brinck, T.; Persson, D.; Pan, J.; Claesson, P.M. In situ investigations of Fe ${ }^{3+}$ induced complexation of adsorbed Mefp-1 protein film on iron substrate. J. Colloid Interface Sci. 2013, 404, 62-71. [CrossRef] [PubMed]

6. Burzio, L.A.; Waite, J.H. Cross-Linking in Adhesive Quinoproteins: Studies with Model Decapeptides. Biochemistry 2000, 39, 11147-11153. [CrossRef] [PubMed]

7. Zhang, F.; Pan, J.; Claesson, P.M. Electrochemical and AFM studies of mussel adhesive protein (Mefp-1) as corrosion inhibitor for carbon steel. Electroch. Acta 2011, 56, 1636-1645. [CrossRef]

8. Hou, R.-Q.; Zhang, F.; Jiang, P.-L.; Dong, S.-G.; Pan, J.-S.; Lin, C.-J. Corrosion inhibition of pre-formed mussel adhesive protein (Mefp-1) film to magnesium alloy. Corros. Sci. 2019, 164, 108309. [CrossRef]

9. Jiang, P.-L.; Hou, R.-Q.; Chen, C.-D.; Sun, L.; Dong, S.-G.; Pan, J.-S.; Lin, C.-J. Controllable degradation of medical magnesium by electrodeposited composite films of mussel adhesive protein (Mefp-1) and chitosan. J. Colloid Interface Sci. 2016, 478, 246-255. [CrossRef]

10. Zhang, F.; Pan, J. Recent Development of Corrosion Protection Strategy Based on Mussel Adhesive Protein. Front. Mater. 2019, 6, 207. [CrossRef]

11. Hansen, D.C.; McCafferty, E. The Effect of Various Naturally Occurring Metal-Binding Compounds on the Electrochemical Behavior of Aluminum. J. Electrochem. Soc. 1996, 143, 114-119. [CrossRef]

12. Sababi, M.; Zhang, F.; Krivosheeva, O.; Forslund, M.; Pan, J.; Claesson, P.M.; Dedinaite, A. Thin Composite Films of Mussel Adhesive Proteins and Ceria Nanoparticles on Carbon Steel for Corrosion Protection. J. Electrochem. Soc. 2012, 159, C364-C371. [CrossRef]

13. Zhang, F.; Chen, C.; Hou, R.; Li, J.; Cao, Y.; Dong, S.; Lin, C.; Pan, J. Investigation and application of mussel adhesive protein nanocomposite film-forming inhibitor for reinforced concrete engineering. Corros. Sci. 2019, 153, 333-340. [CrossRef]

14. Berman, D.; Erdemir, A.; Sumant, A.V. Graphene: A new emerging lubricant. Mater. Today 2014, 17, 31-42. [CrossRef]

15. Berman, D.; Deshmukh, S.A.; Sankaranarayanan, S.K.R.S.; Erdemir, A.; Sumant, A.V. Extraordinary Macroscale Wear Resistance of One Atom Thick Graphene Layer. Adv. Funct. Mater. 2014, 24, 6640-6646. [CrossRef]

16. Khan, Z.H.; Kermany, A.R.; Öchsner, A.; Iacopi, F. Mechanical and electromechanical properties of graphene and their potential application in MEMS. J. Phys. D Appl. Phys. 2017, 50, 53003. [CrossRef]

17. Liu, Y.; Ai, K.; Lu, L. Polydopamine and Its Derivative Materials: Synthesis and Promising Applications in Energy, Environmental, and Biomedical Fields. Chem. Rev. 2014, 114, 5057-5115. [CrossRef] [PubMed]

18. Jang, H.; Kim, J.-H.; Kang, H.; Bae, D.; Chang, H.; Choi, H. Reduced graphene oxide as a protection layer for Al. Appl. Surf. Sci. 2017, 407, 1-7. [CrossRef]

19. Chen, S.; Shen, B.; Zhang, F.; Hong, H.; Pan, J. Mussel-Inspired Graphene Film with Enhanced Durability as a Macroscale Solid Lubricant. ACS Appl. Mater. Interfaces 2019, 11, 31386-31392. [CrossRef] 
20. Cheng, J.; Chen, S.; Zhang, F.; Shen, B.; Lu, X.; Pan, J. Corrosion- and wear-resistant composite film of graphene and mussel adhesive proteins on carbon steel. Corros. Sci. 2020, 164, 108351. [CrossRef]

21. Suci, P.A.; Geesey, G.G. Use of Attenuated Total Internal Reflection Fourier Transform Infrared Spectroscopy To Investigate Interactions between Mytilus edulis Foot Proteins at a Surface. Langmuir 2001, 17, 2538-2540. [CrossRef]

22. Fant, C.; Hedlund, J.; Höök, F.; Berglin, M.; Fridell, E.; Elwing, H. Investigation of Adsorption and Cross-Linking of a Mussel Adhesive Protein Using Attenuated Total Internal Reflection Fourier Transform Infrared Spectroscopy (ATR-FTIR). J. Adhes. 2010, 86, 25-38. [CrossRef]

23. Chalker, P.; Bull, S.; Rickerby, D. A review of the methods for the evaluation of coating-substrate adhesion. Mater. Sci. Eng. A 1991, 140, 583-592. [CrossRef]

24. Zaffora, A.; Di Quarto, F.; Kura, C.; Sato, Y.; Aoki, Y.; Habazaki, H.; Santamaria, M. Electrochemical Oxidation of Hf-Nb Alloys as a Valuable Route to Prepare Mixed Oxides of Tailored Dielectric Properties. Adv. Electron. Mater. 2018, 4, 1800006. [CrossRef]

25. Zhang, F.; Brinck, T.; Brandner, B.D.; Claesson, P.M.; Dedinaite, A.; Pan, J. In situ confocal Raman micro-spectroscopy and electrochemical studies of mussel adhesive protein and ceria composite film on carbon steel in salt solutions. Electroch. Acta 2013, 107, 276-291. [CrossRef]

26. Butz, F.; Aita, H.; Takeuchi, K.; Ogawa, T. Enhanced mineralized tissue adhesion to titanium over polystyrene assessed by the nano-scratch test. J. Biomed. Mater. Res. Part A 2005, 74, 164-170. [CrossRef] [PubMed]

27. Hang, Y.; Liu, G.; Huang, K.; Jin, W. Mechanical properties and interfacial adhesion of composite membranes probed by in-situ nano-indentation/scratch technique. J. Membr. Sci. 2015, 494, 205-215. [CrossRef]

28. Ashraf, A.; Wu, Y.; Wang, M.C.; Yong, K.; Sun, T.; Jing, Y.; Haasch, R.T.; Aluru, N.R.; Nam, S. Doping-Induced Tunable Wettability and Adhesion of Graphene. Nano Lett. 2016, 16, 4708-4712. [CrossRef] [PubMed]

29. Danner, E.; Kan, Y.; Hammer, M.U.; Israelachvili, J.N.; Waite, J.H. Adhesion of Mussel Foot Protein Mefp-5 to Mica: An Underwater Superglue. Biochemistry 2012, 51, 6511-6518. [CrossRef] [PubMed]

30. Ji, Y.; Yang, X.; Ji, Z.; Zhu, L.; Ma, N.; Chen, D.; Jia, X.; Tang, J.; Cao, Y. DFT-Calculated IR Spectrum Amide I, II, and III Band Contributions of N-Methylacetamide Fine Components. ACS Omega 2020, 5, 8572-8578. [CrossRef]

31. Chen, C.; Hou, R.; Zhang, F.; Dong, S.; Claesson, P.M.; Lin, C.; Pan, J. Heating-Induced Enhancement of Corrosion Protection of Carbon Steel by a Nanocomposite Film Containing Mussel Adhesive Protein. J. Electrochem. Soc. 2017, 164, C188-C193. [CrossRef]

32. Mallamace, F.; Corsaro, C.; Mallamace, D.; Vasi, S.; Vasi, C.; Dugo, G. The role of water in protein's behavior: The two dynamical crossovers studied by NMR and FTIR techniques. Comput. Struct. Biotechnol. 2015, 13, 33-37. [CrossRef] [PubMed]

33. Sever, M.J.; Weisser, J.T.; Monahan, J.; Srinivasan, S.; Wilker, J.J. Metal-Mediated Cross-Linking in the Generation of a MarineMussel Adhesive. Angew. Chem. Int. Ed. 2004, 43, 448-450. [CrossRef] [PubMed]

34. Matin, M.A.; Islam, M.M.; Bredow, T.; Aziz, M.A. The Effects of Oxidation States, Spin States and Solvents on Molecular Structure, Stability and Spectroscopic Properties of Fe-Catechol Complexes: A Theoretical Study. Adv. Chem. Eng. Sci. 2017, 7, 137-153. [CrossRef]

35. Al-Mashta, F.; Sheppard, N.; Lorenzelli, V.; Busca, G. Infrared study of adsorption on oxygen-covered $\alpha-\mathrm{Fe}_{2} \mathrm{O}_{3}$ : Bands due to adsorbed oxygen and their modification by co-adsorbed hydrogen or water. J. Chem. Soc. Faraday Trans. 1 Phys. Chem. Condens. Phases 1982, 78, 979-989. [CrossRef]

36. Cai, S.; Singh, B.R. Identification of $\beta$-turn and random coil amide III infrared bands for secondary structure estimation of proteins. Biophys. Chem. 1999, 80, 7-20. [CrossRef]

37. Witkowski, A.; Wójcik, M. Infrared spectra of hydrogen bond a general theoretical model. Chem. Phys. 1973, 1, 9-16. [CrossRef]

38. Mostad, A.; Ottersen, T.; Rømming, C.; Hammarström, S.; Lousberg, R.J.J.C.; Weiss, U. On the Structure of L-DOPA (2S-3-(3,4Dihydroxyphenyl)alanine). Acta Chem. Scand. 1971, 25, 3549-3560. [CrossRef]

39. Leng, C.; Liu, Y.; Jenkins, C.; Meredith, H.; Wilker, J.J.; Chen, Z. Interfacial Structure of a DOPA-Inspired Adhesive Polymer Studied by Sum Frequency Generation Vibrational Spectroscopy. Langmuir 2013, 29, 6659-6664. [CrossRef]

40. Guo, H.; Sun, Y.; Niu, X.; Wei, N.; Pan, C.; Wang, G.; Zhang, H.; Chen, H.; Yi, T.; Chen, X. The preparation of poly-levodopa coated capillary column for capillary electrochromatography enantioseparation. J. Chromatogr. A 2018, 1578, 91-98. [CrossRef] 